\title{
Trade Spaces in Crewed Spacecraft Atmosphere Revitalization System Development
}

\author{
Jay L. Perry ${ }^{1}$, Robert M. Bagdigian ${ }^{2}$ and Robyn L. Carrasquillo ${ }^{3}$ \\ NASA George C. Marshall Space Flight Center, MSFC, Alabama, 35812
}

\begin{abstract}
Developing the technological response to realizing an efficient atmosphere revitalization system for future crewed spacecraft and space habitats requires identifying and describing functional trade spaces. Mission concepts and requirements dictate the necessary functions; however, the combination and sequence of those functions possess significant flexibility. Using a closed loop environmental control and life support (ECLS) system architecture as a starting basis, a functional unit operations approach is developed to identify trade spaces. Generalized technological responses to each trade space are discussed. Key performance parameters that apply to functional areas are described.
\end{abstract}

\section{Nomenclature}

g $\quad=$ gram

$h=$ hour

$k g \quad=$ kilogram

$k W \quad=$ kilo-Watt

$m g \quad=$ milligram

$M P a \quad=$ mega-Pascal, absolute

psia = pound per square inch, absolute

$W \quad=$ Watt

$\mu \mathrm{m} \quad=$ micrometer

\section{Introduction}

$\mathrm{T}$ HROUGHOUT its history, crewed space exploration has challenged the frontiers of technological complexity and human performance to expand our knowledge of the universe. As space exploration objectives have expanded and mission duration has increased from early missions lasting only minutes to permanently crewed space stations, the technological challenge of economically and reliably providing the crewmembers with a safe, comfortable cabin environment has long engaged life support system designers. Accommodating longer missions drives spacecraft designers toward greater operational autonomy and minimal reliance on expendable resources-key features of a modern spacecraft environmental control and life support (ECLS) system suited for crewed exploration beyond low Earth orbit (LEO).

The ECLS system on board the ISS embodies the greatest progression toward operational autonomy and reduced expendable resource consumption. Even so, significant improvement is necessary because some of the equipment solutions deployed on board the ISS continue to depend on timely, reliable logistical support from Earth. Because of this dependence, they are expensive to maintain and require a significant time commitment from both the crew and ground support personnel to ensure they are functioning properly. Operational autonomy of these systems is limited. To extend humanity's reach to exploration objectives beyond LEO, these deficiencies in the ISS ECLS system must be addressed. To this end, the advanced systems must sever the ties to the ground for logistical and mission operations support. The systems must be economically efficient with respect to mass, volume, and power consumption while the monitoring and control system will need to be more autonomous.

\footnotetext{
${ }^{1}$ Senior Engineer, Environmental Control Systems, Engineering Directorate, Space Systems Department, ECLS System Development Branch/ES62, NASA MSFC, MSFC, Alabama 35812.

${ }^{2}$ Branch Chief, Engineering Directorate, Space Systems Department, ECLS System Development Branch/ES62, NASA MSFC, MSFC, Alabama 35812.

3 Technical Assisant, Engineering Directorate, Space Systems Department, ECLS System Development Branch/ES62, NASA MSFC, MSFC, Alabama 35812.
} 


\section{ISS as the Basis for ECLS System Developmental Progression}

The technical approach for designing the ISS's ECLS system defined six principle functional categories - control atmospheric pressure, condition atmosphere, respond to emergency conditions, control atmospheric carbon dioxide $\left(\mathrm{CO}_{2}\right)$ partial pressure and trace contaminants, provide water, and prepare for extravehicular activity (EVA) operations. Five ECLS subsystems address these requirements. The subsystems include atmosphere control and supply (ACS), atmosphere revitalization (AR), temperature and humidity control (THC), water recovery and management (WRM), and fire detection and suppression (FDS) ${ }^{1-3}$ Similar requirement and functional decomposition may be adopted for missions beyond LEO; however, there may be mission-specific nuances to achieve the most efficient design solution depending upon the mission objectives.

Embarking upon crewed space exploration missions beyond LEO depends greatly on the availability of suitable closed loop life support system technologies. A key distinction between these missions and all crewed space missions to date is the challenge presented by supporting human life far from logistics depots. Mission economics make storing all the supplies required to support human life on board the spacecraft impractical. Four objectives for ECLS system designers for improving crewed exploration mission economics beyond LEO are the following:

1) To replace expendable process technologies with regenerable process technologies where feasible.

2) To ensure the ECLS system is simple and easily maintained.

3) To ensure the ECLS system is highly reliable.

4) To achieve a high degree of mass balance closure.

Process technology development efforts must address common functional requirements for a series of possible missions that progress from an open mass balance to a nearly closed mass balance. Selecting and developing core process technologies that enable a broad range of crewed space exploration objectives remains a technological challenge.

\section{A. ISS Atmosphere Revitalization Subsystem Experience and Opportunities for Improvement}

Applying experience gained from crewed spacecraft operations, particularly that acquired during the Mir and ISS programs, greatly assist the progression toward a regenerable, reliable, closed ECLS system architecture. Chief areas for attention toward improvement are the following: ${ }^{4}$

1) Reliance on logistics resupply and consumable resources.

2) System operational robustness and complexity.

3) Life cycle economics.

These areas for improvement mirror the four objectives stated previously. Using the ISS as the starting basis, the following presents examples of how these areas for improvement might be addressed.

1. Reduce Resupply and Consumable Resources

Replacing expendable process technologies with regenerable technologies is central to realizing a central ECLS system operational goal and enabling exploration beyond LEO. Driving the ECLS AR subsystem design toward greater degrees of loop closure is a core technology development area. Incorporating carbon dioxide reduction in the AR subsystem architecture is a beginning step. The ISS AR subsystem has moved incrementally toward loop closure by including functional hooks and scars to accommodate $\mathrm{CO}_{2}$ reduction equipment. This equipment is based on the Sabatier reactor. ${ }^{5}$ While a major technical step, improvement can still be realized by developing methods for recovering hydrogen $\left(\mathrm{H}_{2}\right)$ from the methane $\left(\mathrm{CH}_{4}\right)$ vented by the Sabatier process or developing alternative $\mathrm{CO}_{2}$ reduction processes that consume the process reactants more completely. The Bosch process represents such a process. ${ }^{6}$

The trace contaminant control system (TCCS) on board the ISS U.S. On-orbit Segment (USOS) employs expendable packed beds. [ref. ISS TCCS paper] Although operational experience has allowed the bed service life to be extended from $<1$ year to $>4$ years, the expendable beds still represent a logistics and spares storage burden. ${ }^{7}$ Advancing the USOS TCCS design to incorporate the regenerable bed features used in the Russian On-orbit Segment (ROS) block for micro-impurity removal (BMP) as well as emerging trace contaminant physical adsorbent developments could address the expendable bed issues. Advances in engineered structured sorbents are promising to this end. ${ }^{8-10}$

2. Increase System Operational Robustness and Reduce Complexity

High numbers of equipment components, the need to add components to address unforeseen process challenges, and complicated process control can negatively impact operational robustness and complexity. A balance must be achieved between the need to reduce consumable resource use and efforts to improve overall life cycle economics. For example, although the ISS USOS TCCS uses expendable beds which require careful logistics management, the process design is quite simple leading to very high reliability. TCCS equipment failures are rare compared to other ISS AR subsystem equipment. However, because the TCCS uses expendable beds, it is lacking in an aspect of oper- 
ational robustness because spare beds must be pre-positioned on board the ISS to accommodate some types of cabin contamination events. Storing spare expendable equipment components requires storage volume and transportation resources yielding poor overall life cycle economics. Advancing to regenerable TCCS equipment addresses aspects of operational robustness; however, the addition of valves and process monitoring instrumentation increases the number of equipment components and can complicate process control and introduce more failure mechanisms into the process design.

In addition to process design and control complexity, attention to design details that may affect service life and logistics is important for improving operational robustness. The ISS AR subsystem equipment has experienced instances where unexpected component service life limitations have reduced operational robustness. Two specific examples pertain to ISS TCCS and carbon dioxide removal assembly (CDRA) component service life issues that arose from unexpected time-dependent packed bed property changes. These instances are briefly summarized.

The TCCS process design includes a packed granular lithium hydroxide $(\mathrm{LiOH})$ bed downstream of a thermal catalytic oxidizer. The $\mathrm{LiOH}$ bed, called the sorbent bed assembly (SBA), is located downstream of a thermal catalytic oxidizer (TCO) unit. The SBA removes acidic oxidation products such as hydrogen chloride ( $\mathrm{HCl}$ ) that can be produced if halocarbons enter the TCO unit. Over time the SBA experienced increased flow resistance that ultimately caused loss of TCCS flow control. ${ }^{11}$ Investigation determined that the conversion of the granular LiOH to lithium chloride $(\mathrm{LiCl})$ caused the increased flow resistance. The $\mathrm{LiCl}$ reaction product is extremely hygroscopic and retains large amounts of moisture that contribute to bed granule size attrition and the resulting increased flow resistance. The result is that only a fraction of the $\mathrm{LiOH}$ reacts before flow resistance becomes too great. This result is inefficient because it leaves a significant amount of $\mathrm{LiOH}$ unavailable for reaction. ${ }^{12}$

The zeolite material used in the CDRA beds have been found to undergo size attrition under normal process conditions that include flow reversals, pressure cycling, and temperature cycling. ${ }^{13-14}$ Fine particulates migrating through the bed have been found to contribute to increased flow resistance. Early in the ISS assembly the bed containment failed and zeolite pellets escaped and migrated to downstream components. Containing the zeolite pellets and fine particulate matter to prevent downstream component failures became a long-term challenge to ensuring reliable CDRA operations. ${ }^{15}$

The experience gained from ISS AR subsystem equipment operations indicate that to achieve operational robustness attention early in the design of ECLS system equipment should not be limited to component optimization and efforts to reduce complexity. Early life testing, sometimes at bench scale or the component level, can yield important information necessary to support the need for early design attention to physical properties of packed bed materials and reaction products over extended time periods.

\section{Improve Life Cycle Economics}

All ECLS system equipment must be designed to maximize life cycle economics. The life cycle includes the time from commissioning through retirement. During this period, the equipment must efficiently address factors such as initial launch weight, volume, power consumption, maintenance frequency and duration, in-flight spares storage, and others that may be dictated by the mission design and objectives. Usually this means that all ECLS system equipment must strive to be lightweight, consume little power, and fit in a small volume envelope. Designing regenerable, multi-functional processes is one technique for improving life cycle economics. Of course such multifunctional process designs must be careful to ensure that functional redundancy is fully accommodated. Some multifunctional designs result in sub-optimization of one or more functions so care must be taken in determining how functional combination is accomplished because some multi-functional equipment designs may be too complex or larger than using individual functional elements.

\section{B. Functional Areas for Atmosphere Revitalization Technology Development}

An approach for achieving the improvements in an ECLS AR subsystem design that are needed to produce a highly reliable and efficient closed loop equipment embodiment uses the experience gained during the design, development, testing, and operation of the ISS equipment to identify key areas for improving operational characteristics in the areas of logistics, operational robustness, complexity, and life cycle economics. This approach identifies specific AR subsystem functional unit operations and cultivates development of candidate process technologies that provide each necessary function. Opportunities to implement inventive principles such as segmentation, extraction, merging, universality, and inversion must be fully exploited. ${ }^{16-18}$ 
The principle of universality is a beginning step toward a highly reliable, efficient AR subsystem process design and equipment embodiment. Fig. 1 is generalized block flow diagram for an AR subsystem that is capable of application across crewed cabin platforms. The Principle AR subsystem functions include particulate matter removal and disposal; process gas drying and water return to the cabin environment; trace contaminant removal and disposal; carbon dioxide removal and handling; atmospheric gas generation, storage, distribution, and conditioning; and resource recovery for loop closure. ${ }^{19}$

A key feature underlying the block flow diagram presented by Fig. 1 is a core set of AR subsystem unit operations that can be readily configured to operate in either an open loop or closed loop manner. These include particulate matter removal and disposal, water removal and return, trace contaminant removal and disposal, and carbon dioxide removal. This functional core is common across all potential crewed cabin platforms

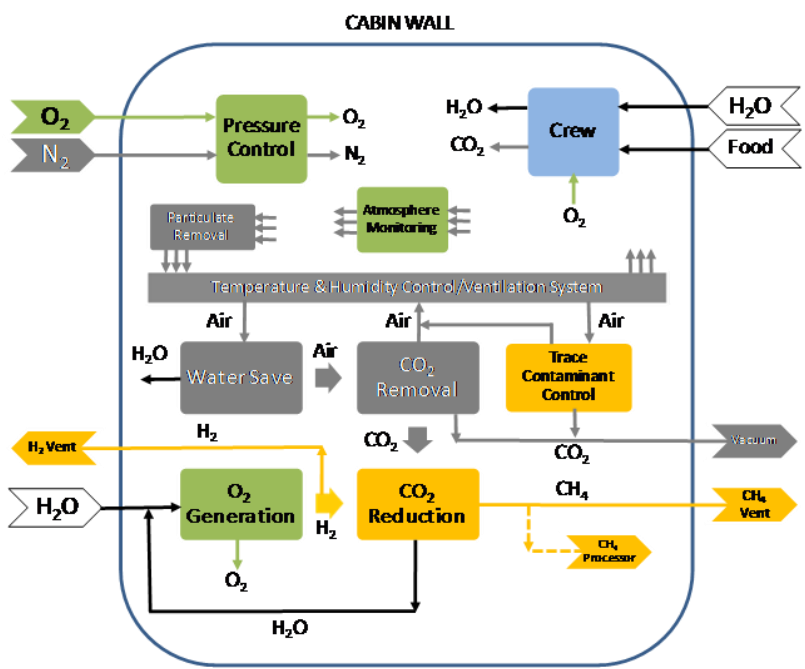

Figure 1. AR subsystem block flow diagram. and must be well integrated with the cabin ventilation system. As shown by Fig. 1 unit operations for $\mathrm{O}_{2}$ generation and resource recovery via $\mathrm{CO}_{2}$ reduction and/or in-situ resource utilization (ISRU) can be added to close the AR subsystem process loop. The ISS AR subsystem architecture serves as the basis for Fig. 1. Some functional stages, such as trace contaminant control, may be in a different order or combined with other functional stages for future crewed cabin platforms.

\section{Atmosphere Revitalization Functional Trace Spaces}

The block flow diagram presented by Fig. 1 can be expanded into functional trade spaces. Fig. 2 expands the functional areas and highlights candidate technological candidates that may be competitive in each trade space. Process technologies that may be applied within each trade space are summarized. The trade spaces presented by Fig. 2 are grouped into three primary AR functional areas-particulate removal, core AR subsystem, and loop closure.

\section{A. Particulate Removal Functions}

Particulate removal and disposal is a challenge during all phases of a crewed space exploration mission. Particulate generation from the crew and their activities must be addressed for all space exploration objectives. The challenge is compounded by dust intrusion into the cabin during surface exploration operations. Functional trade spaces to address this challenge include primary screening, secondary separation, and tertiary separation. This 3-stage approach is considered to be a most viable technical solution. ${ }^{20}$

Primary screening removes course particulate matter $>100 \mu \mathrm{m}$ and fibers. Screens have been used widely in crewed space vehicles to prevent lint and debris from fouling air-breathing equipment. Screens used on board the ISS have proven to be very effective and easily maintained. Features to consider in this trade space include the screen's geometry, materials of construction, and mesh rating.

4

American Institute of Aeronautics and Astronautics 
Secondary separation is most important for heavy particulate matter loading that is likely during surface exploration operations when dust and debris intrusion from outside the cabin can become a challenge. Inertial separation techniques are of interest in this trade space. The targeted particulate size range is $>2 \mu \mathrm{m}$ to $<100 \mu \mathrm{m}$. Impingement and cyclone separators are techniques that may be considered within this trade space. Secondary separation may also prove useful for use on crewed platforms that are not engaged in surface exploration operations due to their regenerable nature.

Tertiary separation, like primary screening, is necessary during all mission phases. The particulate size fraction $<2 \mu \mathrm{m}$ is addressed in this trade space. Media filtration is the most common technique. Regenerating media filters is typically challenging. Therefore most media filters are expendable. Features to consider for this trade space are filter geometry, media type, materials of construction. The media be rated according to high efficiency particulate air (HEPA) or ultra-low particulate air (ULPA) filter performance specifications. The media may be in a fixed housing or contained in a cassette that allows for either manual or automated advancement of fresh filter media into the air flow path.

\section{B. Core AR Subsystem Functions}

The core AR subsystem functions are those that are common across all crewed space exploration mission platforms. The core functions include gas drying, trace contaminant removal, and $\mathrm{CO}_{2}$ removal. In the process order presented by Fig. 1 and Fig. 2, the capability to configure the core AR subsystem equipment string to function within a closed ECLS system architecture is implied. Concepts that

To provide the most flexibility toward ECLS system loop closure, the gas drying stages must allow for a water saving feature. The capability to reconfigure the process to vent water overboard can be useful feature. The bulk drying function removes moisture from the process gas stream. Techniques in this trade space typically include regenerable adsorbent and membrane processes. The need for a residual drying stage is not always necessary if the downstream processes are tolerant to gas dewpoint ranging between $-30{ }^{\circ} \mathrm{C}$ and $-20{ }^{\circ} \mathrm{C}$. Residual drying techniques within the trade space include packed adsorbent beds and structured sorbents.

The trace contaminant control function removes the volatile organic compounds (VOCs) and other gaseous contaminants from the cabin atmosphere. Locating the function in the AR subsystem equipment string upstream of the $\mathrm{CO}_{2}$ removal function helps to ensure that the $\mathrm{CO}_{2}$ product meets the purity requirements for reduction processes. A variety of process technology options and considerations exist for this trade space. Typical options include granular or pellet adsorbent media, structured adsorbent media, and various oxidation catalysts.

All upstream functions serve as pre-processing unit operations for the $\mathrm{CO}_{2}$ removal unit. The $\mathrm{CO}_{2}$ removal function is the principle core AR function. Trade space options include granular or pellet adsorbent media, structured adsorbent media on metallic or non-metallic substrates, and reactive media.

\section{Loop Closure Functions}

Functional trade spaces that are specific to a closed loop ECLS system include $\mathrm{O}_{2}$ generation and $\mathrm{CO}_{2}$ reduction. Carbon dioxide removed from the cabin atmosphere is also conditioned and stored within the AR loop closure functional envelope.

Carbon dioxide reduction provides a necessary step toward realizing a truly closed loop ECLS system. Carbon dioxide from the core AR elements and $\mathrm{H}_{2}$ from the $\mathrm{O}_{2}$ generation process are the feed gases. Some feed gas conditioning for temperature, pressure, and moisture content is inherent in the overall loop closure functional scheme. Handling the $\mathrm{CO}_{2}$ feed may also require assessment of storage options such as tanks or solid state storage techniques using adsorbent media. Hydrogen storage and buffering may also be accomplished by tanked storage or metal hydride media. Options for processing $\mathrm{CO}_{2}$ reduction product gases such as $\mathrm{CH}_{4}$ must also be considered. Thermal pyrolysis and plasma pyrolysis are processes of interest within the $\mathrm{CH}_{4}$ processing trade space.

Both Fig. 1 and Fig. 2 imply water electrolysis as the process technology for the $\mathrm{O}_{2}$ generation function because $\mathrm{H}_{2}$ and $\mathrm{O}_{2}$ is a product from the feed. Within the $\mathrm{O}_{2}$ generation trade space, decisions concerning operating pressure and electrolytic cell stack design are myriad. Options for drying and distributing the product $\mathrm{H}_{2}$ and $\mathrm{O}_{2}$ must also be considered.

Opportunities exist for merging some core AR functions and loop closure functions. Developments in photolytic and gas phase $\mathrm{CO}_{2}$ electrolysis may prove to be quite important to reducing the resource requirements associated with a closed loop AR subsystem. Their operational flexibility and suitability for operating in open loop applications will need close scrutiny. 


\section{Atmosphere Revitalization Performance Targets}

Performance targets provide useful tools for comparing candidate process technologies within each trade space. Table 1 lists some relevant performance targets for the trade spaces outlined by Fig. 2. Specifics regarding each performance target are discussed. State-of-the-art (SOA) performance and target values for improvement are summarized. Equipment deployed on board the ISS serves as the basis the SOA performance.

\section{A. Particulate Removal}

The bacteria filter element (BFE) elements used in the ISS USOS weigh approximately $2.2 \mathrm{~kg}$ each and have a particulate loading capacity rating of 50 grams. Each BFE consists of a pre-filter screen followed by pleated HEPA media. Flight performance has found the service life to be approximately 2.4 years. $^{21}$ The specific mass uses 50 grams of particulate matter mass loading over 2.4 years as the calculation basis. Specific power is based on the average filter pressure drop over the 2.4-year service life. During this time and the total mass flow of air that passes through the filter during that time. An energy balance calculation on a single filter element yields $0.03 \mathrm{~W}$ $\mathrm{h} / \mathrm{kg}$ air. Loading with $50 \mathrm{~g}$ of particulate matter and processing approximately $128 \mathrm{~kg}$ air/hour for 2.4 years, the filter specific power is determined. Increasing the total amount of particulate matter that can be accommodated during a maintenance cycle is central to achieving an improved particulate removal and disposal function. Improvement $>60 \%$ compared to ISS process technology is the goal.

\begin{tabular}{|c|c|c|c|c|c|}
\hline $\begin{array}{c}\text { FUNCTIONAL } \\
\text { AREA }\end{array}$ & TRADE SPACE & $\begin{array}{l}\text { PERFORMANCE } \\
\text { PARAMETER \& } \\
\text { UNITS }\end{array}$ & $\begin{array}{c}\text { SOA } \\
\text { VALUE }\end{array}$ & $\begin{array}{l}\text { TARGET } \\
\text { VALUE }\end{array}$ & $\begin{array}{c}\text { SOA } \\
\text { BASIS }\end{array}$ \\
\hline \multirow{2}{*}{$\begin{array}{l}\text { PARTICULATE } \\
\text { REMOVAL \& } \\
\text { DISPOSAL }\end{array}$} & \multirow{2}{*}{$\begin{array}{l}\text { COMBINED - Primary } \\
\text { screening, secondary } \\
\text { separation, \& tertiary } \\
\text { separation }\end{array}$} & $\begin{array}{l}\text { Specific Mass } \\
(\mathrm{kg}-\mathrm{h} / \mathrm{g} \text { PM) }\end{array}$ & 925 & 300 & \multirow{2}{*}{ ISS BFE } \\
\hline & & $\begin{array}{l}\text { Specific Power } \\
\text { (W-h/g PM) }\end{array}$ & 1,615 & 560 & \\
\hline \multirow{7}{*}{$\begin{array}{l}\text { CORE AR } \\
\text { SUBSYSTEM }\end{array}$} & \multirow{5}{*}{$\begin{array}{l}\text { TRACE } \\
\text { CONTAMINANT } \\
\text { REMOVAL }\end{array}$} & $\begin{array}{l}\mathrm{NH}_{3} \text { sorbent capacity } \\
(\mathrm{mg} / \mathrm{g} \text { sorbent })\end{array}$ & 11 & $>50$ & \multirow{5}{*}{ ISS TCCS } \\
\hline & & $\begin{array}{l}\text { Dichloromethane } \\
\text { adsorption capacity } \\
(\mathrm{mg} / \mathrm{g})\end{array}$ & 0.05 & $>0.12$ & \\
\hline & & $\begin{array}{l}\text { Non-methane VOC } \\
\text { oxidation temperature } \\
\left({ }^{\circ} \mathrm{C}\right)\end{array}$ & $>250$ & $<200$ & \\
\hline & & $\begin{array}{l}\text { System Specific Mass } \\
(\mathrm{kg}-\mathrm{h} / \mathrm{kg} \text { air })\end{array}$ & 4 & $<3$ & \\
\hline & & $\begin{array}{l}\text { System Specific Power } \\
\text { (W-h/kg air) }\end{array}$ & 8 & $<2$ & \\
\hline & \multirow{2}{*}{$\mathrm{CO}_{2}$ REMOVAL } & $\begin{array}{l}\text { Specific Mass, } \\
(\mathrm{kg}-\mathrm{h} / \mathrm{kg} \mathrm{CO})_{2}\end{array}$ & 826 & 670 & \multirow{2}{*}{ ISS CDRA } \\
\hline & & $\begin{array}{l}\text { Specific Energy } \\
\left(\mathrm{W}-\mathrm{h} / \mathrm{kg} \mathrm{CO} \mathrm{CO}_{2}\right)\end{array}$ & 2,174 & 560 & \\
\hline \multirow{6}{*}{ LOOP CLOSURE } & \multirow{2}{*}{$\begin{array}{l}\text { OXYGEN } \\
\text { CONDITIONING } \\
\text { (COMPRESSION) }\end{array}$} & $\begin{array}{l}\text { Specific Mass } \\
\left(\mathrm{kg}-\mathrm{h} / \mathrm{kg} \mathrm{O} \mathrm{O}_{2}\right)\end{array}$ & 83 & $<30$ & \multirow{2}{*}{ ISS ORCA } \\
\hline & & $\begin{array}{l}\text { Specific Power } \\
\left(\mathrm{W}-\mathrm{h} / \mathrm{kg} \mathrm{O}_{2}\right)\end{array}$ & 135 & $<100$ & \\
\hline & \multirow{2}{*}{$\begin{array}{l}\text { OXYGEN } \\
\text { GENERATION }\end{array}$} & $\begin{array}{l}\text { Specific Mass } \\
\left(\mathrm{kg}-\mathrm{h} / \mathrm{kg} \mathrm{O} \mathrm{O}_{2}\right)\end{array}$ & 1,560 & 1,000 & \multirow[b]{2}{*}{ ISS OGA } \\
\hline & & $\begin{array}{l}\text { Specific Power } \\
\left(\mathrm{kW}-\mathrm{h} / \mathrm{kg} \mathrm{O}_{2}\right)\end{array}$ & 10 & $<7.5$ & \\
\hline & \multirow{2}{*}{$\mathrm{CO}_{2}$ REDUCTION } & $\begin{array}{l}\text { Specific Mass } \\
\text { (kg-h/kg } \mathrm{H}_{2} \mathrm{O} \text { produced) }\end{array}$ & 1,960 & $<1,600$ & \multirow{2}{*}{$\begin{array}{c}\text { ISS } \\
\text { SABATIER } \\
\text { CRA }\end{array}$} \\
\hline & & $\begin{array}{l}\text { Specific Power } \\
\text { (W-h/kg } \mathrm{H}_{2} \mathrm{O} \text { produced) }\end{array}$ & 2,000 & $<1,600$ & \\
\hline
\end{tabular}

Table 1. AR subsystem functional performance targets.

\section{B. Core AR Subsystem}

Performance targets for trace contaminant control and $\mathrm{CO}_{2}$ removal are the main focus for the core AR subsystem functions. Three specific areas pertaining to trace contaminant control plus overall assembly performance are of interest. Carbon dioxide removal overall performance is the focus for improvement.

Trace contaminant control performance targets address specific areas where adsorbent media mass and power can be reduced. Increasing the equilibrium loading capacity for $\mathrm{NH}_{3}$ and dichloromethane, the two compounds that dictate the size of the ISS TCCS activated carbon bed, can decrease adsorbent bed size leading to overall process equipment mass and power savings. Testing has shown that the TCCS catalytic oxidizer requires $>250{ }^{\circ} \mathrm{C}$ for nonmethane volatile organic compound (VOC) oxidation to light off. Reducing the oxidation temperature can reduce power. TCCS specific mass and specific power targets are quite feasible given that the ISS ROS BMP unit, which contains regenerable carbon beds has an estimated specific power $<2 \mathrm{~W}-\mathrm{h} / \mathrm{kg}$ air and specific mass $<3 \mathrm{~kg}-\mathrm{h} / \mathrm{kg}$ air. ${ }^{22}$

The ISS CDRA is one of the more power intensive AR subsystem processes. This is partly because it contains desiccant beds that provide a residual water removal and water saving function. The $\mathrm{CO}_{2}$ removal beds are heated to a temperature greater than is necessary to facilitate $\mathrm{CO}_{2}$ desorption so that they may serve as thermal capacitors to provide energy to regenerate the desiccant beds. No attempt is made here to extract the residual water removal contribution from the total CDRA performance calculation. That contribution can be represented by the latent heat of vaporization of the desiccant bed's working capacity for water. Bulk water removal and recovery is accomplished on board the ISS by condensing heat exchangers. It is very likely that condensing heat exchangers will be used on board 
future crewed space exploration platforms; however, the AR core processing equipment string may not rely on the condensing heat exchanger to accomplish bulk drying of the process gas stream. The specific mass reduction target is modest at approximately $20 \%$ because many components found in the CDRA such as valves, controllers, and structure will be common to future hardware embodiments that are based on regenerable adsorbent media. The major focus for improvement is power where an improvement approaching 75\% is considered possible by using low thermal mass structured sorbent media in place of packed pellet beds.

\section{AR Loop Closure}

Loop closure techniques functions targeted for improvement over the ISS equipment performance include $\mathrm{O}_{2}$ compression, $\mathrm{O}_{2}$ generation, and $\mathrm{CO}_{2}$ reduction. Pertinent considerations for improvement are summarized.

Equipment for compressing $\mathrm{O}_{2}$ and producing $\mathrm{O}_{2}$ by electrolyzing water are on board the ISS. This equipment serves as the basis for the starting values for improvement. Oxygen compression is accomplished on board the ISS by the oxygen recharge compressor assembly (ORCA). This device is capable of delivering $\mathrm{O}_{2}$ at $24.8 \mathrm{MPa}(3,600$ psia). Oxygen compression is one of the more power intensive functions. Targets to improve specific mass and power by approximately $60 \%$ have been selected.

Electrolyzing water is a power intensive method to produce $\mathrm{O}_{2}$. The ISS oxygen generator assembly (OGA) consumes $3,573 \mathrm{~W}$ to produce $5.4 \mathrm{~kg} \mathrm{O} /$ day. Because of safety concerns, the electrolysis cell stack is contained in a pressure dome. This safety is a significant component of the OGA's $350 \mathrm{~kg}$ mass. Improvement of electrolysisbased process equipment is anticipated to be incremental in nature. Therefore targeted performance improvements over the ISS OGA of approximately $30 \%$ will be challenging.

Carbon dioxide reduction equipment to be demonstrated on board the ISS will provide improved SOA estimates as well as serve as the basis for performance targets. Early estimates for the specific power and mass based on $\mathrm{H}_{2} \mathrm{O}$ production rate are provided by Table 1 . It is evident from carefully analyzing Table 1 that any process technology option that successfully merges $\mathrm{CO}_{2}$ removal, $\mathrm{O}_{2}$ generation, and $\mathrm{CO}_{2}$ reduction functions can make a highly significant impact on the overall closed loop AR process economics.

\section{Summary}

A functional, unit operation based approach to defining relevant functional areas for improvement and process technology development has been presented. Such an approach is considered to be most effective in the absence of clearly mandated crewed space exploration objectives. Common functions across multiple crewed space exploration platforms are addressed. Core functions must possess sufficient flexibility to be configured for either open loop or closed loop operation with minimal modification or growth in size or complexity. Performance goals that use the ISS as the starting basis are presented. The possible performance improvement compared to the ISS ECLS system is projected to range from $30 \%$ to $60 \%$. These improvements are realized by addressing specific areas in the SOA ECLS system architecture where resource consumption, design robustness, and life cycle economics can be most greatly influenced.

\section{Conclusion}

Developing the process technologies needed to extend crewed space exploration beyond LEO continues to be the greatest challenge for ECLS system designers. Looking upon the ISS as the best example of the continued progression in ECLS system design toward loop closure and exploiting the experience gained from operating that system are vital to future long-term, crewed space exploration successes. The commonality that exists between the ISS ECLS system architecture and the architectures suitable for future crewed space exploration platforms must be acknowledged and used to benefit the next great exploration initiatives. It is recognized that a generalized, functional approach to ECLS system technology development may not fully optimize technical solutions for a specific mission scenario. Working on common functions, however, offers the advantage of developing technologies that are most applicable to a broad range of space exploration objectives which have not yet been defined. As well, the technical products from such a technology development effort will not become obsolete if new exploration objectives are not defined in the near term because they can also satisfy the functional requirements of ECLS systems of current platforms either as replacements, upgrades, or enhancements. The generalized, functional approach provides a framework for sustained investment to advance ECLS system process technologies that can make near-term impacts as well as enable future crewed space exploration endeavors. 


\section{References}

${ }^{1}$ Wieland, P. O., "Designing for Human Presence in Space-An Introduction to Environmental Control and Life Support Systems," NASA RP-1324, 1994, pp. 5-22.

${ }^{2}$ Reuter, J. L., Turner, L. D., and Humphries, W. R., "Preliminary Design of the Space Station Environmental Control and Life Support System," $18^{\text {th }}$ Intersociety Conference on Environmental Systems, SAE 881031, San Francisco, California, 1988, pp. 1-4.

${ }^{3}$ Humphries, W. R., Reuter, J. L., and Schunk, R. G., "Space Station Environmental Control and Life Support Distribution and Loop Closure Studies," $16^{\text {th }}$ Intersociety Conference on Environmental Systems, SAE 860942, San Diego, California, 1986, pp. 1-3.

${ }^{4}$ Carrasquillo, R. L., "ISS ECLSS Technology Evolution for Exploration," 43 ${ }^{\text {rd }}$ AIAA Aerospace Sciences Meeting and Exhibit, AIAA-2005-0337, Reno, Nevada, 2005, pp. 3-7.

${ }^{5}$ James C. Knox, J. C., Campbell, M., Miller, L. A., Mulloth, L., Varghese, M., and Luna, B., "Integrated Test and Evaluation of a 4-Bed Molecular Sieve, Temperature Swing Adsorption Compressor, and Sabatier Engineering Development Unit," $36^{\text {th }}$ International Conference on Environmental Systems, SAE 2006-01-2271,

${ }^{6}$ Wagner, R. C., Carrasquillo, R., Edwards, J., and Holmes, R., "Maturity of the Bosch $\mathrm{CO}_{2}$ Reduction Technology for Space Station Application," $18^{\text {th }}$ Intersociety Conference on Environmental Systems, SAE 880995, San Francisco, California, 1988.

${ }^{7}$ Perry, J. L., Cole, H. E., and El-Lessy, H. N., “An Assessment of the International Space Station's Trace Contaminant Control Subassembly Process Economics,” NASA TM-2005-214008, 2005.

${ }^{8}$ Perry, J., Howard, D., Knox, J.C., Junaedi, C., "Engineered Structured Sorbents for the Adsorption of Carbon Dioxide and Water Vapor from Manned Spacecraft Atmospheres-Applications and Testing 2008/2009," 39 ${ }^{\text {th }}$ International Conference on Environmental Systems, SAE 2009-01-2444, Savannah, Georgia, 2009.

${ }^{9}$ Roychoudhury, S., Walsh, D., and Perry, J., "Resistively-Heated Microlith-Based Adsorber for Carbon Dioxide and Trace Contaminant Removal," $35^{\text {th }}$ International Conference on Enviromental Systems, SAE 2005-01-2866, Rome, Italy, 2005.

${ }^{10}$ Roychoudhury, S., Walsh, D., and Perry, J., "Microlith Based Sorber for Removal of Environmental Contaminants," $34^{\text {th }}$ International Conference on Environmental Systems, SAE 2004-01-2442, Colorado Springs, Colorado, 2004.

${ }^{11}$ Johnson, S., "Characteristics of Post-Sorbent and High Temperature Catalytic Oxidizer Beds after Long-Term On-orbit Use," 37 th International Conference on Environmental Systems, SAE 2007-01-3180, Chicago, Illinois, 2007.

${ }^{12}$ Perry, J. L. and Aguilera, T., "Root Cause Assessment of Pressure Drop Rise of a Packed Bed of Lithium Hydroxide in the International Space Station Trace Contaminant Control System," $39^{\text {th }}$ International Conference on Environmental Systems, SAE 2009-01-2433, Savannah, Georgia, 2009.

${ }^{13}$ Dutton, F. D. and Chiu, C., "Carbon Dioxide Removal Assembly/Four Bed Molecular Sieve Adsorbent Material Geometry Comparison Test. NASA ECLSS/TECH/EL96-001, 1996.

${ }^{14}$ Mullier, M. A., Seville, J. P. K., Herbert, F., and Adams, M. J., "The Abrasive Wear of Silica Sand Agglomerates," Tribology International, Vol. 26, No. 5, Oct 1993, pp. 329-334.

${ }^{15}$ Reysa, R. P., Lumpkin, J. P., El Sherif, D., Kay, R., and Williams, D. E., "Characteristics International Space Station Carbon Dioxide Removal Assembly Desiccant/Adsorbent Bed Orbital Replacement Unit Redesign," $37^{\text {th }}$ International Conference on Environmental Systems, SAE 2007-01-3181, Chicago, Illinois, 2007.

${ }^{16}$ Perry, J. L. and Howard, D., "Spacecraft Life Support System Process Technology Maturation using Stage Gate Methodology," 37 $7^{\text {th }}$ International Conference on Environmental Systems, SAE 2007-01-3045, Chicago, Illinois, 2007.

${ }^{17}$ Hipple, J., "Solve Problems Inventively," Chemical Engineering Progress, April 2005, p. 47.

${ }^{18}$ Hipple, J., "Use TRIZ to Plan, Forecast, and Think Strategicially," Chemical Engineering Progress, June 2005, p. 48.

${ }^{19}$ Perry, J. L., Carrasquillo, R. L., and Harris, D. W., "Atmosphere Revitalization Technology Development for Crewed Space Exploration," 44 ${ }^{\text {th }}$ AIAA Aerospace Sciences Meeting and Exhibit, AIAA 2006-140, Reno, Nevada, 2006.

${ }^{20}$ Agui, J. H., and Stocker, D. P., "NASA Lunar Dust Filtration and Separations Workshop Report", NASA TM-2009215821, 2009, p.18.

${ }^{21}$ Perry, J. L., “International Space Station Bacteria Filter Element Service Life Evaluation,” NASA TM-2005-213846, 2005.

${ }^{22}$ Mitchell, K. L., Bagdigian, R. M., Carrasquillo, R. L., Carter, D. L., Franks, G. D., Holder, D. W., Hutchens, C. F., Ogle, K. Y., Perry, J. L., and Ray, C. D., "Technical Assessment of Mir-1 Life Support Hardware for the International Space Station," NASA TM-108441, p. 52. 